\title{
SÍNDROME DE ANTICORPO ANTIMEMBRANA BASAL
}

Identificação: RKAF, 16 anos

História da moléstia atual: Paciente relatava quatro meses de evolução da doença quando foi internada em nossa enfermaria. No período havia iniciado quadro de tosse produtiva com secreção esverdeada contendo laivos de sangue, sudorese vespertina, adinamia e perda de peso (aproximadamente 10\% peso corporal). Após um mês passou a apresentar hematúria macroscópica e palidez.

Hábitos pessoais: Tabagismo dois anos/ maço/dia, etilismo ocasional. Medicamento em uso: Prednisona $60 \mathrm{mg} / \mathrm{dia}$.

Ao exame clínico: Paciente apresentava-se em bom estado geral, afebril, anictérica, acianótica, hipocorada $++/ 4+$, hidratada, sem linfoadenomegalias.

Aparelho cardiovascular: Ritmo cardíaco regular a dois tempos, bulhas normofonéticas, Pressão arterial: $140 \times 95 \mathrm{mmHg}$.

Aparelho respiratório: Murmúrio vesicular presente bilateralmente, diminuído em base de hemitórax direito, com estertores crepitantes em base do hemitórax esquerdo. Abdômen: Plano, flácido, indolor à palpação superficial e profunda.

Extremidades: Boa perfusão periférica, sem edema ou cianose.

Exames complementares: Creatinina $(\mathrm{mg} / \mathrm{dl})$ (25/06/2003) 0,8 (0I/08) 2,7 (I2/08) 2,I * submetida a pulsoterapia com solumedrolâ em 29/07 por três dias consecutivos

FAN: não reagente p-ANCA: negativo c-ANCA: negativo

Urina I: Leucócitos: $120.000 / \mathrm{ml}$, eritrócitos: 9.000.000/ml com dismorfismo: $++/+++$ Urina 24 h: Diurese: $1580 \mathrm{ml}$. Depuração de Creatinina: $30 \mathrm{ml} / \mathrm{min}$. Proteinúria 24h: 3.08g Dosagem sérica de anticorpo antimembrana basal: Resultado de 7,0 EU/mL (valores < 5,0 negativo; 5, I - |4,9 limítrofe; > I5,0 positivo) * Observando-se que tal dosagem foi realizada após o início da imunossupressão.

Hipótese diagnóstica: Doença por anticorpo antimembrana basal (Síndrome de Goodpasture).

Exame de imagem

FIGURA I

Exame anatomopatológico

Figuras $2 \mathrm{~A}$ e $2 \mathrm{~B}$
Figura I - Tomografia de Tórax: velamento em "vidro fosco", comprometimento difuso de ambos campos pulmonares, processo mais acentuado nas bases, poupando ápices

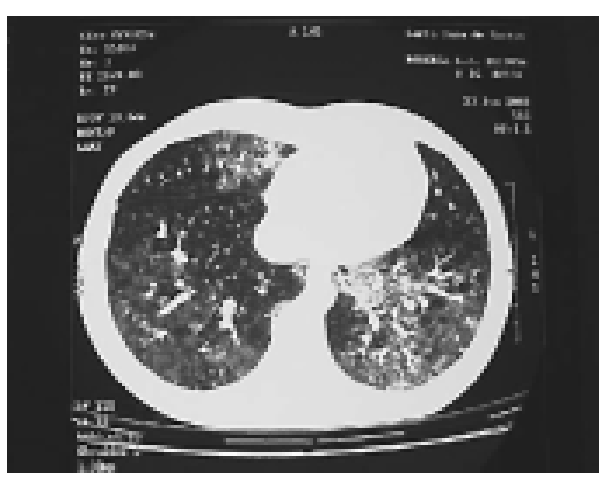

Figura 2A - Biópsia renal (HE 400X): Glomerulonefrite proliferativa exsudativa necrosante; Crescentes celulares e fibrocelulares na totalidade dos glomérulos viáveis; Esclerose glomerular global de cerca de $30 \%$ dos glomérulos amostrados; Alterações degenerativas e necróticas dos túbulos

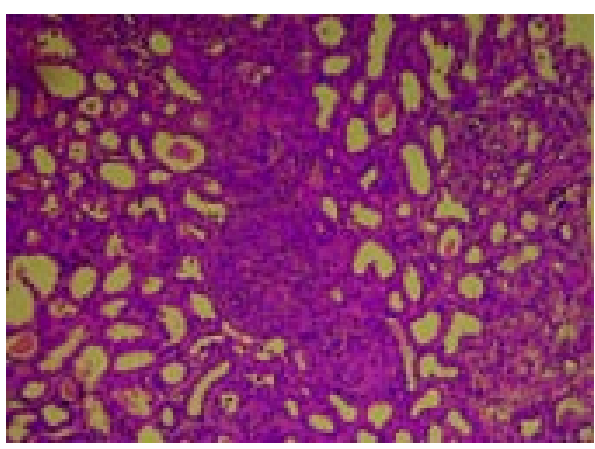

Figura 2B - Biópsia renal imunofluorescência com anticorpo anti-IgG (400X). Depósitos lineares ao longo da membrana basal glomerular, difusos e homogêneos, de lgG policlonal e C3 consistentes com glomerulonefrite crescência mediada por anticorpo antimembrana basal glomerular

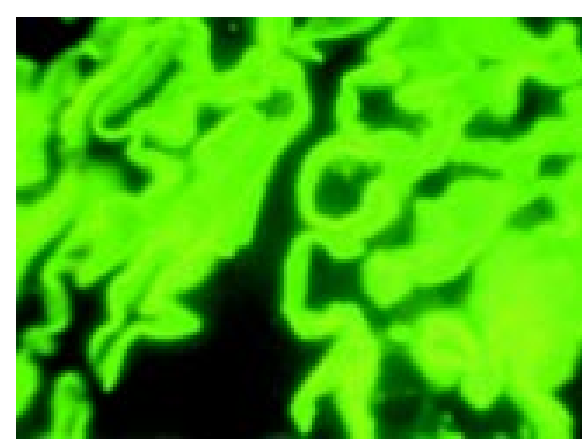




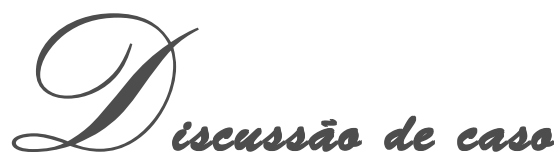

\section{Discussão}

A síndrome de Goodpasture é uma patologia mediada pelo sistema imunológico, na qual auto-anticorpos contra a cadeia a 3 (IV) do colágeno tipo IV se ligam à membrana basal, alveolar e glomerular, causando glomerulonefrite progressiva e hemorragia pulmonar. Descrita inicialmente como uma síndrome pulmão-rim, em 1919 por Goodpasture 1,2, o epônimo foi primeiramente utilizado por Stanton e Tange em 1958. A presença de autoanticorpos apresentando depósito linear foi demonstrada nos anos $60^{3}$.

O mecanismo de injúria renal e pulmonar é complexo. No rim, os anticorpos se ligam à membrana basal, ativam a cascata do complemento e de proteases, tal ativação provoca ruptura da barreira glomerular e da cápsula de Bowman, causando proteinúria, hematúria e facilitando a formação de crescentes. O setor celular com os linfócitos T CD4 e CD8 +, macrófagos e neutrófilos participam da agressão produzindo, entre outros, interleucina 12 e interferon g que medeiam a formação de crescentes ${ }^{4}$.

A doença apresenta maior prevalência na população branca, com distribuição etária bimodal, com maior freqüência aos 30 e aos 60 anos. Grande parte dos pacientes apresenta combinação de glomerulonefrite rapidamente progressiva e hemorragia alveolar, podendo em 30\% a $40 \%$ dos casos exibir acometimento renal isolado caracterizado por hematúria, proteinúria leve a moderada, ou mesmo insuficiência renal aguda. $\mathrm{O}$ acometimento pulmonar é mais comum em homens jovens, manifesta-se clinicamente por dispnéia e tosse, com ou sem hemoptise. A presença de infiltrado alveolar ao raio-X simples de tórax pode acompanhar o caso, porém é pouco específico. Anticorpos anticitoplasma de neutrófilo (Anca) estão presentes em 30\% dos pacientes com doença antimembrana basal ${ }^{5}$.

Ao contrário de outras vasculites Anca positiva, histologicamente o padrão da doença é tipicamente monofásico, com lesões glomerulares de estadio de evolução semelhante ${ }^{6}$. No exame de imunofluorescência quase todos os pacientes apresentam depósitos lineares de $\lg G$ na membrana basal, C3 e, ocasionalmente, $\lg A$ e $\lg M$.

A doença não tratada geralmente apresenta um prognóstico ruim. A introdução do tratamento combinado de plasmaferese (remoção de anticorpos patogênicos), agentes alquilantes tais como a ciclofosfamida (prevenção de síntese de novos anticorpos) e corticoterapia (ação antinflamatória) revolucionaram a evolução da doença.

O prognóstico na apresentação do quadro clinico é pior se há oligúria, fibrose renal avançada ou mais que $50 \%$ de crescentes na biópsia renal. Nível elevado de creatinina (creatinina pré-tratamento $>6,6 \mathrm{mg} / \mathrm{dl}$ ) ou necessidade de diálise também se associam com pior evolução. A sobrevida em um ano é cerca de $75 \%$ a $90 \%$.

Pacientes com doença renal terminal que apresentam hemoptise devem ser tratados. O quadro pulmonar é, freqüentemente, responsivo a plasmaferese. A presença de hemorragia alveolar é indicação formal de tratamento intensivo, a despeito da severidade do acometimento renal.

Carlos Alberto Balda

Marcello fabiano de Franco

Andrei Alkmim Teixeira, Erika Ferraz Helena Mendonça

Disciplina de Nefrologia da Universidade Federal de São Paulo UNIFESP-EPM, São Paulo, SP.

\section{Referências}

I. Salama AD, Levy JB, Lightstone L, Pusey CD: Goodpasture's disease. Lancet 200I; 358:917-20.

2. Bolton WK, Nephrology Forum: Goodpasture's syndrome. Kidney Int 1996; 50:1753-66.

3. Stanton MC, Tange JD: Goodpasture's syndrome. Aust N Z J Med 1958; 7: I32-44. 4. Jayne DR, Marshall PD, Jones SJ, Lockwood CM: Autoantibodies to GBM and neutrophil cytoplasm in rapidly progressive glomerulonephritis. Kidney Int 1990; 37:965-70.

5. Pusey CD: Anti-glomerular basement membrane disease. Kidney Int 2003; 64:1535-50.

6. Hudson BG, Tryggvason K, Sundaramoorthy M, Neilson EG: Alport's syndrome, goodpasture's syndrome, and type IV collagen. New Engl J Med 2003; 348:2543-56. 